\title{
Training to identify red flags in the acute care of trauma: who are the patients at risk for early death despite a relatively good prognosis? An analysis from the TraumaRegister DGU ${ }^{\circledR}$
}

Philip-C. Nolte ${ }^{1 \dagger}$, David Häske ${ }^{2,3+}$, Rolf Lefering ${ }^{4}$, Michael Bernhard ${ }^{5}$, Sebastian Casu ${ }^{6}$, Susanne Frankenhauser ${ }^{7}$, Andreas Gather ${ }^{1}$, Paul A. Grützner ${ }^{1}$, Matthias Münzberg ${ }^{1,7^{*}}$ and the TraumaRegister DGU ${ }^{8}$

\begin{abstract}
Background: In the acute care of trauma, some patients with a low estimated risk of death die suddenly and unexpectedly. In this study, we aim to identify predictors for early death within $24 \mathrm{~h}$ following hospital admission in low-risk patients.

Methods: The TraumaRegister DGU ${ }^{\circledR}$ was used to collect records of patients who were primarily treated in a participating hospital between 2004 and 2013 with a RISC II score below 10\%.
\end{abstract}

Results: During the study period, 64,379 patients met the inclusion criteria. The mean RISC II score was 2.0\%, and the mean ISS was $16 \pm 9$. The overall hospital mortality rate was $2.1 \%$, and $0.5 \%$ of patients $(n=301)$ died within the first $24 \mathrm{~h}$. A SPB of $\leq 90 \mathrm{mmHg}$ was associated with an increased risk of death $(p<0.001)$. An AlS abdomen score of $\geq 3$ was associated with increased risk of death within the first $24 \mathrm{~h}(p<0.001)$. A high risk of early death was also seen in patients with an AIS score (thorax) $\geq 3 ; 51 \%$ of those who died died within the first $24 \mathrm{~h}(p<$ 0.005). Death in patients over 60 years was more common after $24 \mathrm{~h}(p<0.001)$. Patients with an ASA score of $\geq 3$ were more likely to die after the first $24 \mathrm{~h}(p<0.001)$.

Conclusions: Indicators predicting a high risk of early death in patients with a low RISC II score include a SPB $\leq 90$ $\mathrm{mmHg}$ and severe chest and abdominal trauma. Emergency teams involved in the acute care of trauma patients should be aware of these "red flags" and treat their patients accordingly.

Keywords: Trauma, Revised injury severity classification (RISC-score), Trauma registry, Early death, Red flags, Prehospital, Life support

\footnotetext{
* Correspondence: matthias.muenzberg@bgu-ludwigshafen.de

Philip-C. Nolte and David Häske shared first authorship.

'Department of Trauma and Orthopedic Surgery, BG Trauma Center Ludwigshafen, 67071 Ludwigshafen, Germany

${ }^{7}$ Department of Rescue and Emergency Medicine, BG Trauma Center Ludwigshafen, 67071 Ludwigshafen, Germany

Full list of author information is available at the end of the article
}

C C The Author(s). 2020 Open Access This article is licensed under a Creative Commons Attribution 4.0 International License, which permits use, sharing, adaptation, distribution and reproduction in any medium or format, as long as you give appropriate credit to the original author(s) and the source, provide a link to the Creative Commons licence, and indicate if changes were made. The images or other third party material in this article are included in the article's Creative Commons licence, unless indicated otherwise in a credit line to the material. If material is not included in the article's Creative Commons licence and your intended use is not permitted by statutory regulation or exceeds the permitted use, you will need to obtain permission directly from the copyright holder. To view a copy of this licence, visit http://creativecommons.org/licenses/by/4.0/ The Creative Commons Public Domain Dedication waiver (http://creativecommons.org/publicdomain/zero/1.0/) applies to the data made available in this article, unless otherwise stated in a credit line to the data. 


\section{Introduction}

Injuries account for more than five million annual deaths worldwide [1]. The impact on the younger population is more severe, where trauma is the leading cause of death among those aged 15-29 years [1]. Patients with extensive injuries and, therefore, a high Injury Severity Score (ISS) have decreased chances of survival [2]. It is broadly accepted that these severely injured patients need to be treated with great alertness and awareness of their fragile situation, receiving extensive therapy.

For prognostication and the adjustment of mortality rates, not only the anatomical injuries as displayed by the ISS are important, but also the physiological responses to injury. Thus, the Revised Injury Severity Classification (RISC) score was developed and updated to its 2nd version (RISC II) in 2014 [3, 4]. The RISC II score was shown to be superior to the existing scoring systems and is used in the context of the TraumaRegister DGU ${ }^{\circ}$ (TR-DGU) for outcome adjustment [4]. Patients presenting with low RISC II scores have higher survival chances, but experience shows that there are patients who seem to fall through the cracks and, despite good prognosis and seemingly no disastrous injuries, die suddenly and unexpectedly [5-7]. If those cases ultimately die, and especially if they die shortly after hospital admission, a detailed analysis might help to understand the lifethreatening mechanisms in trauma. Therefore, this study aimed to identify "red flags" (indicators signaling danger) in the acute care of trauma patients that account for a high risk of early death, despite their good prognosis.

\section{Materials and methods}

\section{Database}

The TraumaRegister DGU (TR-DGU) of the German Trauma Society (Deutsche Gesellschaft für Unfallchirurgie, DGU) was founded in 1993. The aim of this multicenter database is to collect pseudonymized and standardized documentation of severely injured patients.

Data are collected prospectively in four consecutive time phases from the site of the accident until discharge from hospital: (A) prehospital phase, (B) emergency room and initial surgery, $(C)$ intensive care unit, and (D) discharge. The documentation includes detailed information on demographics, injury pattern, comorbidities, pre- and in-hospital management, a course on the intensive care unit, and relevant laboratory findings (including data on transfusion and case outcomes). The inclusion criterion is admission to hospital via an emergency room with subsequent ICU/IMC care or reaching the hospital with vital signs and die before admission to the ICU.

The infrastructure for documentation, data management, and data analysis is provided by the AUC-Academy for Trauma Surgery (AUC-Akademie der Unfallchirurgie $\mathrm{GmbH}$ ), a company affiliated to the
German Trauma Society. The scientific leadership is provided by the Committee on Emergency Medicine, Intensive Care and Trauma Management (Sektion Notfall-, Intensivmedizin und Schwerverletztenversorgung (NIS)) of the German Trauma Society. The participating hospitals submit their pseudonymized data into a central database via a web-based application. Scientific data analysis is approved according to a peer review procedure established by Sektion NIS.

The participating hospitals are primarily located in Germany (90\%), but an increasing number of hospitals in other countries also contribute data (including Austria, Belgium, China, Finland, Luxembourg, Slovenia, Switzerland, the Netherlands, and the United Arab Emirates). Currently, approximately 35,000 cases from nearly 700 hospitals are entered into the database each year. Participation in the TraumaRegister $\mathrm{DGU}^{\circ}$ is voluntary. The TraumaNetwork DGU ${ }^{\circ}$ is a network of hospitals which are organized according to uniform standards of care and quality assurance and are according to the $\mathrm{DGU}^{\circ}$ white book of trauma care (Weißbuch Schwerverletztenversorgung) based on their structure, resources in staff, equipment, and tasks, resulting in level 1 to 3 trauma centers [8]. Level 1 trauma centers represent centers with the highest resources, whereas level 3 centers have limited resources. For hospitals associated with TraumaNetwork $\mathrm{DGU}^{\circ}$, however, the entry of at least a basic data set is obligatory for reasons of quality assurance. The present study follows the publication guidelines of the TR-DGU and is registered as TR-DGU project TR-DGU-2014-059.

\section{Prognostic score}

The Revised Injury Severity Classification (RISC) score was developed and used for outcome adjustment in the context of the TraumaRegister DGU ${ }^{\circ}$ since 2003 [3].

The currently used RISC II (Revised Injury Severity Classification, version 2) score was developed in more than 30,000 cases from the TR-DGU documented in 2010 and 2011, and repeatedly validated in the following years. It consists of the following predictors: AIS (Abbreviated Injury Scale) severity level of worst and secondworst injury, head injury, age, sex, pupil reactivity and size, pre-injury health status, trauma mechanism (penetrating), blood pressure, acidosis (base deficit), coagulopathy (INR), hemoglobin, and cardiopulmonary resuscitation [4]. Missing values are included as a separate category for all variables except for age and injuries. The RISC II score was superior to the existing scoring systems, including the original RISC score [4].

\section{Patient selection}

Primary admitted patients treated in a participating German hospital between 2004 and 2013 were included if 
their RISC II prognosis was below 10\% risk of death. Further exclusions were age $=0$, early transfer out within $48 \mathrm{~h}$ (no outcome available), ISS < 4 (RISC not validated), and minor injuries (maximum AIS $\leq 2$ ) not treated on intensive care unit (ICU). Patients were divided into survivors and non-survivors, and nonsurvivors were further divided into early deaths $(<24 \mathrm{~h})$ and late deaths.

\section{Outcome indicators}

Various common variables were tested for their ability to serve as early indicators ("red flags") of death. The variables were grouped into the subcategories "patientrelated indicators" [American Society of Anesthesiologists (ASA) score and age], vital sign-related indicators [first prehospital Glasgow Coma Scale (GCS), pre- and intrahospital systolic blood pressure (SBP)], systemrelated indicators (air rescue vs. ground rescue, admission during on-call hours), level of trauma center (level 1 to 3 ), and injury-related indicators (AIS head $\geq 3$, AIS thorax $\geq 3$, AIS abdomen $\geq 3$, AIS pelvis $\geq 4$, AIS extremities $\geq 3$ ).

\section{Statistical analysis}

Data are presented as mean with standard deviation $( \pm$ $\mathrm{SD}$ ) and median for continuous variables and as percentages for categorical variables. Pairwise comparisons (survivor vs. non-survivor, and early vs. late deaths) were performed with the chi-squared test and Mann-Whitney $U$ test, as appropriate. Statistical analysis was performed using SPSS, version 24.0 (IBM Inc., Armonk, NY, USA). $p$ values $\leq 0.05$ were considered statistically significant.

\section{Results}

A total of 64,379 patients $(72.7 \%$ male, mean age 44 years) met the criteria and were included. The hospital mortality rate was $2.1 \%(n=1,372)$, and 301 of these ( $0.5 \%$ of all cases or $22 \%$ of those who died) died within the first $24 \mathrm{~h}$ of hospital admission.

The mean RISC II score for all included patients was $2.0 \%$ and matched well with the observed mortality rate. The average ISS was $16.4 \pm 9.2$, and $49 \%$ fulfilled the ISS $\geq 16$ criterion. The RISC II score and the ISS were highest $(5.9 \% ; 22.0 \pm 12.3)$ in the group of patients who died within $24 \mathrm{~h}$. The type and mechanism of trauma were typical for a western-European country with mainly blunt trauma (95.7\%), and with over half of them (60.1\%) being traffic related. The basic demographic data and parameters are presented in Table 1.

\section{Patient-related indicators}

In the non-survivor group, patients with an age of 60 years and above died significantly more often after $24 \mathrm{~h}$ [58.2\% $(n=623)$ vs. $41.9 \%(n=126)$ within $24 \mathrm{~h} ; p<$ 0.001]. Based on the ASA classification, 4333 (9.3\%) patients had an ASA of $\geq 3$ before the accident. The evaluation showed that patients with an ASA classification $\geq$ 3 were more likely to die after $24 \mathrm{~h}$ than within the first 24 h $(p<0.001)$.

\section{Vital sign-related indicators}

A prehospital GCS of 8 or below was documented in 5918 cases (9.8\%). Of the 261 patients with GCS $\leq 8$ who died in hospital, only 74 died within $24 \mathrm{~h}(p=0.004)$.

The mortality of patients with a prehospital SBP $\leq 90$ $\mathrm{mmHg}$ was $14.5 \%(n=175)$, which was significantly higher compared to shocked patients in survivors $(8.9 \%$;

Table 1 Survivorship according to demographic data and outcome indicators

\begin{tabular}{|c|c|c|c|c|c|c|c|}
\hline & & Survivor & Non-survivor & $\boldsymbol{p}$ value & Early deaths $<24 \mathrm{~h}$ & Late deaths $>24 \mathrm{~h}$ & $\boldsymbol{p}$ value \\
\hline Age $\geq 60$ years & $n(\%)$ & $13,887(22.0)$ & $749(54.6)$ & $p<0.001$ & $126(41.9)$ & $623(58.2)$ & $p<0.001$ \\
\hline ASA 3-4 & $n(\%)$ & $3987(8.7)$ & $346(35.9)$ & $p<0.001$ & $47(23.4)$ & $299(39.2)$ & $p<0.001$ \\
\hline ISS & Mean \pm SD & $16.3 \pm 9.1$ & $20.7 \pm 11.0$ & $p<0.001$ & $22.0 \pm 12.3$ & $20.3 \pm 10.5$ & $p=0.083$ \\
\hline RISC II predicted mortality & Mean \pm SD & $1.9 \pm 2.3$ & $5.3 \pm 2.9$ & $p<0.001$ & $5.9 \pm 2.8$ & $5.1 \pm 2.9$ & $p<0.001$ \\
\hline Air rescue & $n(\%)$ & $15,527(25.4)$ & $341(25.6)$ & $p=0.912$ & $68(23.4)$ & $273(26.2)$ & $p=0.328$ \\
\hline Admission during on-call hours & n (\%) & $42,108(67.6)$ & $854(63.6)$ & $p=0.002$ & $201(68.4)$ & $653(62.2)$ & $p=0.054$ \\
\hline \multicolumn{8}{|l|}{ Trauma center } \\
\hline Level 1 & $n(\%)$ & $38,518(61.1)$ & $878(64.0)$ & $p=0.08$ & $165(54.8)$ & $713(66.6)$ & $p<0.001$ \\
\hline Level 2 & & $20,085(31.9)$ & $411(30.0)$ & & $109(36.2)$ & $302(28.2)$ & \\
\hline Level 3 & & $4404(7.0)$ & $83(6.0)$ & & $27(9.0)$ & $56(5.2)$ & \\
\hline $\mathrm{SBP} \leq 90 \mathrm{mmHg}$, prehospital & $n(\%)$ & $5021(8.9)$ & $175(14.5)$ & $p<0.001$ & $67(25.9)$ & $108(11.4)$ & $p<0.001$ \\
\hline $\mathrm{SBP} \leq 90 \mathrm{mmHg}$, on admission & $n(\%)$ & $2736(4.8)$ & $125(10.3)$ & $p<0.001$ & $54(21.3)$ & $71(7.4)$ & $p<0.001$ \\
\hline $\mathrm{GCS} \leq \mathbf{8}$, prehospital & $n(\%)$ & $5657(9.5)$ & $261(20.3)$ & $p<0.001$ & $74(26.5)$ & $187(18.6)$ & $p=0.004$ \\
\hline
\end{tabular}

ASA American Society of Anesthesiologists, BE base excess, GCS Glasgow Coma Scale, Hb hemoglobin, ISS Injury Severity Score, RISC II Revised Injury Severity Classification version 2, SBP systolic blood pressure 
$n=5021 ; p<0.001)$. In patients who died within $24 \mathrm{~h}$, a prehospital SBP $\leq 90 \mathrm{mmHg}$ was documented in $25.9 \%$ and, therefore, significantly more often than in patients who died later $(11.4 \%, p<0.001)$.

A total of $10.3 \%(n=125)$ of the patients who died in the hospital, but only $4.8 \%(n=2736)$ of survivors had an intrahospital SBP $\leq 90 \mathrm{mmHg}(p<0.001)$. In patients who died within $24 \mathrm{~h}$, an intrahospital SBP $\leq 90 \mathrm{mmHg}$ was documented in $21.3 \%$, which is significantly more frequent than in those who died later $(7.4 \%, p<0.001)$.

\section{System-related indicators}

There was no difference in mortality when comparing air rescue vs. ground transportation $(p=0.912)$. Patients who died within $24 \mathrm{~h}$ were similarly distributed between the groups (ground rescue $0.5 \%$ vs. air rescue $0.4 \% ; p=0.328$ ).

There were a total of $42,962(67.5 \%)$ patients admitted to the hospital during on-call hours, of which 854 (2.0\%) died. During regular hours, 489 of 20,653 (2.4\%) patients died, which was significantly more than within on-call hours $(p=0.002)$. Of all patients who died during oncall hours, $23.5 \%$ died within the first $24 \mathrm{~h}$, whereas during regular work hours only $19.0 \%$ of patients died within $24 \mathrm{~h}(p=0.054)$.

Most patients [39,396 (61.2\%)] were admitted to a level 1 trauma center, $20,496(31.8 \%)$ to a level 2 center, and $4487(7.0 \%)$ to a level 3 center $(p=0.08)$. Of all patients who died within the first $24 \mathrm{~h}$, mortality was higher in the level 3 trauma centers $(32.5 \%)$ compared to the level $1(18.7 \%)$ and $2(26.5 \%)$ trauma centers $(p<0.001)$.

\section{Injury-related indicators}

Details to the injury patterns are displayed in Table 2. A total of 16,730 (26.0\%) patients had a relevant head injury (AIS $\geq 3$ ). Patients who died had significantly more head injuries (39.4\%) than survivors $(25.7 \%, p<0.001)$. However, among the 541 patients who died with an AIS head $\geq 3$, there was no significant difference between early and late deaths $(p=0.196)$.

A total of $24,980(38.8 \%)$ patients had an AIS thorax $\geq$ 3 . In the non-survivor group, $46.3 \%$ of patients had an AIS thorax $\geq 3$, compared to $38.6 \%$ in the survivor group $(p<0.001)$. Patients with an AIS thorax $\geq 3$ died significantly quicker than those with a lower AIS thorax score $(p<0.005)$.

There were $7002(10.9 \%)$ patients with an AIS abdomen $\geq 3$, of which significantly more died than survived $(p<0.001)$. Also, patients with severe abdominal injuries died quicker (24.9\% within 24 h vs. $14.2 \%$ after 24 h; $p<$ 0.001).

The mortality rate was higher among the 3430 patients with an AIS pelvis $\geq 4$. Here, of the non-survivors, 115 (8.4\%) had an AIS pelvis of $\geq 4$, while among the survivors only $5.3 \%$ had an AIS $\geq 4(p<0.001)$. However, there was no significant difference between death before or after $24 \mathrm{~h}(p<0.111)$.

Among all patients, $27.3 \%(n=17,584)$ had an AIS extremities score $\geq 3$. Also, in patients with severely injured extremities, death was significantly more frequent than survival (31.3\% vs. $27.2 \% ; p<0.001)$, but no difference was detected in the temporal distribution.

\section{Discussion}

The death of a patient with a good prognosis was often described as an "unexpected" death. However, a prognosis is nothing more than an estimated probability, that is, if one out of 10 patients each with a prognosis of $10 \%$ dies, then this is exactly what the score expected. However, in individual cases that died, it would be very important to understand why these patients died, despite the absence of critical findings. This study aimed to identify predictors for early death in low-risk patients. We found that a systolic blood pressure $\leq 90 \mathrm{mmHg}$ in the pre- or intrahospital setting, as well as severe chest and abdominal trauma, as represented by an AIS $\geq 3$, could account for a high risk of early death in patients with a RISC II score below $10 \%$. Those indicators should especially alert emergency teams in the trauma room and can be recognized as "red flags" in the acute care of trauma patients.

Higher age is an independent risk factor for traumarelated death; patients are twice as likely to die if they are 65 years and older [7-11]. In older patients, the preexistence of typical age-dependent medical conditions, such as diabetes, high blood pressure, reduced respiratory, and cardiac capacity, as well as polypharmacy, is the rule rather than the exception [12]. Following

Table 2 Survivorship according to injury-related indicators

\begin{tabular}{|c|c|c|c|c|c|c|c|}
\hline \multicolumn{2}{|c|}{ Relevant injury (AIS $\geq 3$ ) } & \multirow{2}{*}{$\frac{\text { Survivor }}{16,189(25.7)}$} & \multirow{2}{*}{$\begin{array}{l}\text { Non-survivor } \\
541(39.4)\end{array}$} & \multirow{2}{*}{$\begin{array}{l}p \text { value } \\
p<0.001\end{array}$} & \multirow{2}{*}{$\begin{array}{l}\text { Early deaths }<24 \mathrm{~h} \\
109(36.2)\end{array}$} & \multirow{2}{*}{$\begin{array}{l}\text { Late deaths }>24 \mathrm{~h} \\
432(40.3)\end{array}$} & \multirow{2}{*}{$\begin{array}{l}p \text { value } \\
p=0.196\end{array}$} \\
\hline Head & $n(\%)$ & & & & & & \\
\hline Thorax & $n(\%)$ & 24,345 (38.6) & $635(46.3)$ & $p<0.001$ & $154(51.2)$ & $481(44.9)$ & $p<0.005$ \\
\hline Abdomen & $n(\%)$ & 6775 (10.8) & $227(16.5)$ & $p<0.001$ & $75(24.9)$ & $152(14.2)$ & $p<0.001$ \\
\hline Pelvis (AIS $\geq 4$ ) & $n(\%)$ & $3315(5.3)$ & $115(8.4)$ & $p<0.001$ & $32(10.6)$ & $83(7.7)$ & $p=0.111$ \\
\hline Extremities & $n(\%)$ & $17,155(27.2)$ & $429(31.3)$ & $p<0.001$ & 95 (31.6) & $334(31.2)$ & $p=0.901$ \\
\hline
\end{tabular}


trauma, those conditions contribute to an increased risk of complications, such as sepsis and multi-organ failure [9, 12], thereby contributing to a higher mortality rate [13]. In line with the literature, we detected significantly higher mortality in the 60-year-old or above patient group. However, whereas overall mortality was higher in the patients aged 60 years and above, younger patients were more prevalent in the early death group. We suggest that this phenomenon is most likely due to the different mechanisms of injury (e.g., high-velocity motor vehicle accident) in the younger patients, followed by higher injury severities. Also, younger trauma victims might better compensate for the consequences of an injury that makes them look quite normal on admission (i.e., the values used for prediction). The higher overall mortality in the elderly might also not derive from the trauma itself but from independent medical conditions or late complications, such as sepsis or multiorgan failure. The coexistence of higher age and medical conditions also explains our findings regarding the ASA score. Our results show that patients with an ASA score $\geq$ 3 were more likely to die. Furthermore, similar to the higher age, patients with an ASA score $\geq 3$ died significantly more often after $24 \mathrm{~h}$ than in the first $24 \mathrm{~h}$ following hospital admission. In older patients with low RISC II scores, care should be taken to avoid late complications occurring after $24 \mathrm{~h}$, such as sepsis, while younger patients are at risk of sudden death, most likely due to higher injury severity. However, we did not find a higher age or ASA score to be a "red flag" for death within $24 \mathrm{~h}$.

Various studies have shown that traumatic brain injury is one of the leading causes of death due to trauma and was found to be responsible for about half of them $[6,14,15]$. In the non-survivor group of our study collective, there were significantly more patients with a prehospital GCS $\leq$ 8 . However, patients with a GCS $\leq 8$ were more likely to die after the first $24 \mathrm{~h}$; therefore, a GCS $\leq 8$ was not considered to be a "red flag" for early death. These findings are concordant with those of prior studies, demonstrating that death due to traumatic brain injury is not the predominant cause in the early hours following trauma $[6,7,14]$.

Importantly, we were able to show that hypotensive shock, as represented by a prehospital and intrahospital $\mathrm{SBP} \leq 90 \mathrm{mmHg}$, accounts for significantly higher risk of death in general and within $24 \mathrm{~h}$ in particular. We, therefore, consider a low SBP to be an important "red flag." Since hypotensive shock in trauma patients is most likely due to hemorrhage, this becomes especially relevant because Kleber et al. found that death by exsanguination is preventable in $73.1 \%$ of patients [16].

There is ongoing discussion about whether air rescue or ground rescue is more beneficial for trauma patients. Recent literature shows increasing evidence that air rescue might be superior to ground rescue in major trauma [1618]. However, a review from 2015 could not determine an accurate benefit for air rescue [17]. In our collection of low RISC II patients, we could not detect a difference in survival rate when comparing air and ground rescue; both subgroups had a mortality rate of $2.1 \%$. Also, no difference was detected in the temporal distribution of death.

To evaluate whether there is a so-called weekend effect, we compared the mortality of patients who were admitted to the hospital during on-call hours to those who were admitted during regular work hours. Mortality was significantly lower following admission during on-call hours. There was no significant difference when comparing early vs. late deaths, although a tendency towards higher mortality within $24 \mathrm{~h}$ was seen in patients admitted during oncall hours. These results are in line with the findings of other groups who found no difference or even lower mortality during weekends/weeknights (on-call hours) compared to weekdays [18-20]. A possible explanation for this finding could be that during on-call hours, a higher awareness for critically injured patients and less distraction from routine daytime work exist.

We could not detect a difference in mortality between the three types of trauma centers, even though patients admitted to a level 1 trauma center had better chances to survive the first $24 \mathrm{~h}$ compared to level 2 or 3 trauma centers; however, no significant differences were found in overall mortality. This effect might be due to more aggressive treatment in a level 1 center, which allows patients to survive the first $24 \mathrm{~h}$.

Severe chest and abdominal trauma have been described to account for high mortality within 1 and $6 \mathrm{~h}$, respectively, in a trauma center with over one third of patients presenting with penetrating trauma [21]. Interestingly, in a trauma center in the Netherlands with more than $90 \%$ blunt trauma, chest injury was also one of the major causes of early death [6]. Our results are in line with these findings, as we found a severe chest and abdominal injury, as represented by an AIS $\geq 3$, to be responsible for high mortality and early deaths. Given the observation, that death following abdominal trauma is most likely due to hemorrhage [22]. Our finding stresses the importance of thorough initial examination and continuous reevaluation (e.g., clinical and sonography) of patients with abdominal trauma. These patients may present with sufficient vital parameters on admission but become worse over a short period of time. Likewise, blunt chest trauma is challenging to treat as it can cause a wide variety of injuries (e.g., pneumothorax, pericardial effusion, aortic injuries, myocardial contusion) and symptoms, and is referred to as "clinical chameleon" [23]. Again, patients can present hemodynamically stable on initial evaluation although suffering a life-threatening injury. Therefore, care should be taken not to underestimate the severity of the injury.

An AIS $\geq 3$ of the head and the extremities and an AIS $\geq 4$ of the pelvis were all associated with significantly higher mortality, though no statistical difference was 
found between early or late deaths, and therefore, those parameters did not qualify as "red flags" in the acute care of trauma patients.

Similar impressions as our results were described in the literature, but not with a focus on patients with a statistically good prognosis [7]. In addition to the statistical results, however, it is at least as important how these findings can be integrated into the training and clinical knowledge of health care professionals. It is well known that knowledge flattens with time and can only be maintained through lifetime learning [23-25]. It is also in the hands of those responsible in the emergency medical services, shock room, and hospital to pass on this knowledge. The results of our study make it visible how crucial clinical reasoning is, especially for young professionals, on their way to becoming experts [26]. One must not be blinded by initially good vital signs, but must always see clinical impression, vital values, and medical knowledge in combination.

\section{Limitations}

Our study has limitations. The data were collected from the TraumaRegister $\mathrm{DGU}^{\bullet}$ retrospectively and are therefore considered to be less valid than data from prospective trials. Also, unlike in most clinical trials, testing for data correctness in the TR-DGU is only performed in a small sample of cases. Furthermore, assessed variables such as prehospital or intrahospital blood pressure may have been subject to different prehospital procedures (infusion management, blood components) that vary between countries.

\section{Conclusion}

Based on our analyses, indicators predicting a high risk of early death within $24 \mathrm{~h}$ in patients with a low RISC II score are a systolic blood pressure $\leq 90 \mathrm{mmHg}$ in the prehospital or intrahospital setting, as well as severe chest and abdominal trauma, as represented by an AIS $\geq$ 3. Emergency teams involved in the acute care of trauma patients should be aware of those "red flags" and treat their patients accordingly.

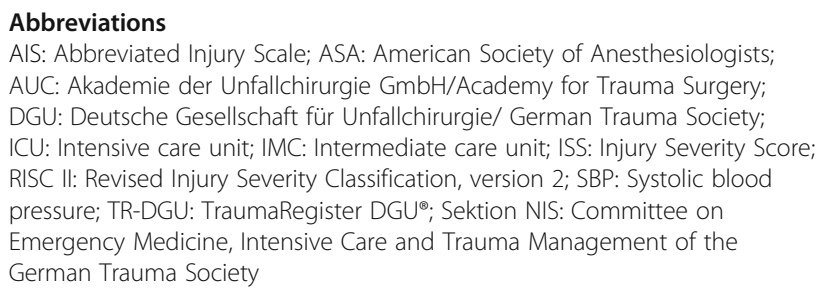

\section{Acknowledgements}

None

\section{Authors' contributions}

$\mathrm{DH}, \mathrm{MM}$, and $\mathrm{RL}$ were the principal investigators in the study and developed the study conception and design. SC and MB helped in developing the study design. The data acquisition was performed by DH and RL. The data analysis and interpretation were performed by $\mathrm{DH}, \mathrm{PCN}$, and RL. RL provided the statistical analysis. SF, AG, and PG helped in the data interpretation. PCN and $\mathrm{DH}$ both contributed equally by drafting the manuscript. All authors read and approved the final manuscript for publication.

Funding

None

Availability of data and materials

None

Ethics approval and consent to participate

The present study follows the publication guidelines of the TR-DGU and is registered as TR-DGU project TR-DGU-2014-059.

\section{Consent for publication}

Data collection, coding, routing, and analysis were in accordance with the legal data protection policy.

\section{Competing interests}

RL declares that his institution receives an ongoing financial support from AUC GmbH who is the owner of the TR-DGU; this service agreement includes the statistical support of scientific analyses of registry data. All other authors declare that they have no competing interests.

\section{Author details}

'Department of Trauma and Orthopedic Surgery, BG Trauma Center Ludwigshafen, 67071 Ludwigshafen, Germany. ${ }^{2}$ Center for Public Health and Health Services Research, University Hospital Tübingen, 72076 Tübingen, Germany. ${ }^{3}$ German Red Cross, Emergency Medical Service, 72764 Reutlingen, Germany. ${ }^{4}$ Institute for Research in Operative Medicine (IFOM), University Witten/Herdecke, Cologne, Germany. ${ }^{5}$ Emergency Department, University Hospital Duesseldorf, 40225 Duesseldorf, Germany. ${ }^{6}$ Department of Intensive Care and Emergency Medicine, Helios Hospital Salzgitter, 38226 Salzgitter,

Germany. ${ }^{7}$ Department of Rescue and Emergency Medicine, BG Trauma Center Ludwigshafen, 67071 Ludwigshafen, Germany. ${ }^{8}$ Committee on Emergency Medicine, Intensive Care and Trauma Management (Sektion NIS) of the German Trauma Society (DGU), Berlin, Germany.

Received: 26 May 2020 Accepted: 5 July 2020

Published online: 03 August 2020

References

1. World Health Organization. WHO | Injuries and violence: the facts 2014. 17. 05. 2020. https://www.who.int/violence_injury_prevention/media/news/2 015/Injury_violence_facts_2014/en/. Accessed 17 May 2020.

2. Baker SP, O'Neill B, Haddon W, Long WB. The injury severity score: a method for describing patients with multiple injuries and evaluating emergency care. J Trauma. 1974;14:187-96.

3. Lefering R. Development and validation of the revised injury severity classification score for severely injured patients. Eur J Trauma Emerg Surg. 2009;35:437-47. https://doi.org/10.1007/s00068-009-9122-0

4. Lefering R, Huber-Wagner S, Nienaber U, Maegele M, Bouillon B. Update of the trauma risk adjustment model of the TraumaRegister DGU ${ }^{\mathrm{Tm}}$ : the revised injury severity classification, version II. Crit Care. 2014;18:476. https://doi.org/ 10.1186/s13054-014-0476-2

5. Acosta JA, Yang JC, Winchell RJ, Simons RK, Fortlage DA, Hollingsworth-Fridlund $P$, et al. Lethal injuries and time to death in a level I trauma center. J Am Coll Surg. 1998;186:528-33. https://doi.org/10.1016/S1072-7515(98)00082-9 ..

6. de Knegt C, Meylaerts SAG, Leenen LPH. Applicability of the trimodal distribution of trauma deaths in a level I trauma Centre in the Netherlands with a population of mainly blunt trauma. Injury. 2008;39:993-1000. https:// doi.org/10.1016/j.injury.2008.03.033

7. Lefering R, Paffrath T, Bouamra O, Coats TJ, Woodford M, Jenks T, et al. Epidemiology of in-hospital trauma deaths. Eur J Trauma Emerg Surg. 2012; 38:3-9. https://doi.org/10.1007/s00068-011-0168-4

8. German Trauma Society. White paper severely injured care. 2019. https:// www.dgu-online.de/fileadmin/published_content/5.Qualitaet_und_ Sicherheit/PDF/2019_DGU_Weissbuch_Schwerverletztenversorgung Vorabdruck.pdf. Accessed 17 May 2020. 
9. Broos PLO, D'Hoore A, Vanderschot P, Rommens PM, Stappaerts KH. Multiple trauma in elderly patients. Factors influencing outcome: importance of aggressive care. Injury. 1993;24:365-8. https://doi.org/10. 1016/0020-1383(93)90096-O

10. Hashmi A, lbrahim-Zada I, Rhee P, Aziz H, Fain M, Friese RS, et al. Predictors of mortality in geriatric trauma patients: a systematic review and meta-analysis. J Trauma Acute Care Surg. 2014;76:894-901. https//doi.org/10.1097/TA.0b013e3182ab0763 .

11. Carr BW, Hammer PM, Timsina L, Rozycki G, Feliciano DV, Coleman JJ. Increased trauma activation is not equally beneficial for all elderly trauma patients. J Trauma Acute Care Surg. 2018;85:598-602. https://doi.org/10.1097/TA.0000000000001986.

12. Kirshenbom D, Ben-Zaken Z, Albilya N, Niyibizi E, Bala M. Older age, comorbid illnesses, and injury severity affect immediate outcome in elderly trauma patients. J Emerg Trauma Shock. 2017;10:146-50. https://doi.org/10.4103/JETS.JETS_62_16.

13. Shoko T, Shiraishi A, Kaji M, Otomo Y. Effect of pre-existing medical conditions on in-hospital mortality: analysis of 20,257 trauma patients in Japan. J Am Coll Surg. 2010;211:338-46. https://doi.org/10.1016/j. jamcollsurg.2010.04.010

14. Bansal V, Fortlage D, Lee JG, Costantini T, Potenza B, Coimbra R Hemorrhage is more prevalent than brain injury in early trauma deaths: the golden six hours. Eur J Trauma Emerg Surg. 2009;35:26-30. https://doi.org/ 10.1007/s00068-008-8080-2.

15. Dutton RP, Stansbury LG, Leone S, Kramer E, Hess JR, Scalea TM. Trauma mortality in mature trauma systems: are we doing better? An analysis of trauma mortality patterns, 1997-2008. J Trauma. 2010;69:620-6. https://doi. org/10.1097/TA.0b013e3181 bbfe2a .

16. Kleber C, Giesecke MT, Tsokos M, Haas NP, Buschmann CT. Trauma-related preventable deaths in Berlin 2010: need to change prehospital management strategies and trauma management education. World J Surg. 2013;37:1154-61. https://doi.org/10.1007/s00268-013-1964-2 .

17. Galvagno SM, Sikorski R, Hirshon JM, Floccare D, Stephens C, Beecher D, et al. Helicopter emergency medical services for adults with major trauma. Cochrane Database Syst Rev. 2015:CD009228. https://doi.org/10.1002/ 14651858.CD009228.pub3

18. Metcalfe D, Perry DC, Bouamra O, Salim A, Lecky FE, Woodford M, et al. Is there a 'weekend effect' in major trauma? Emerg Med J. 2016;33:836-42. https://doi.org/10.1136/emermed-2016-206049 .

19. Carr BG, Reilly PM, Schwab CW, Branas CC, Geiger J, Wiebe DJ. Weekend and night outcomes in a statewide trauma system. Arch Surg. 2011;146: 810-7. https://doi.org/10.1001/archsurg.2011.60

20. Giannoudis V, Panteli M, Giannoudis PV. Management of polytrauma patients in the UK: is there a 'weekend effect'? Injury. 2016;47:2385-90. https://doi.org/10.1016/j.injury.2016.10.007 .

21. Demetriades D, Murray J, Charalambides K, Alo K, Velmahos G, Rhee P, et al. Trauma fatalities: time and location of hospital deaths. J Am Coll Surg. 2004; 198:20-6. https://doi.org/10.1016/j.jamcollsurg.2003.09.003 .

22. Bardes JM, Inaba K, Schellenberg M, Grabo D, Strumwasser A, Matsushima K, et al. The contemporary timing of trauma deaths. J Trauma Acute Care Surg. 2018:84:893-9. https://doi.org/10.1097/TA.0000000000001882.

23. Mohammad A, Branicki F, Abu-Zidan FM. Educational and clinical impact of advanced trauma life support (ATLS) courses: a systematic review. World J Surg. 2014;38:322-9. https://doi.org/10.1007/s00268-013-2294-0 .

24. Häske D, Beckers SK, Hofmann M, Lefering R, Grützner PA, Stöckle U, et al. Subjective safety and self-confidence in prehospital trauma care and learning progress after trauma-courses: part of the prospective longitudinal mixed-methods EPPTC-trial. Scand J Trauma Resusc Emerg Med. 2017;25:79. https://doi.org/10.1186/s13049-017-0426-5 .

25. Häske D, Beckers SK, Hofmann M, Lefering R, Preiser C, Gliwitzky B, et al. Performance assessment of emergency teams and communication in trauma care (PERFECT checklist)-explorative analysis, development and validation of the PERFECT checklist: part of the prospective longitudinal mixed-methods EPPTC trial. PLoS One. 2018:13:e0202795. https://doi.org/10.1371/journal.pone.0202795.

26. Schmidt HG, Rikers RMJP. How expertise develops in medicine: knowledge encapsulation and illness script formation. Med Educ. 2007;41:1133-9. https://doi.org/10.1111/j.1365-2923.2007.02915.x .

\section{Publisher's Note}

Springer Nature remains neutral with regard to jurisdictional claims in published maps and institutional affiliations.

Ready to submit your research? Choose BMC and benefit from:

- fast, convenient online submission

- thorough peer review by experienced researchers in your field

- rapid publication on acceptance

- support for research data, including large and complex data types

- gold Open Access which fosters wider collaboration and increased citations

- maximum visibility for your research: over $100 \mathrm{M}$ website views per year

At BMC, research is always in progress.

Learn more biomedcentral.com/submissions 